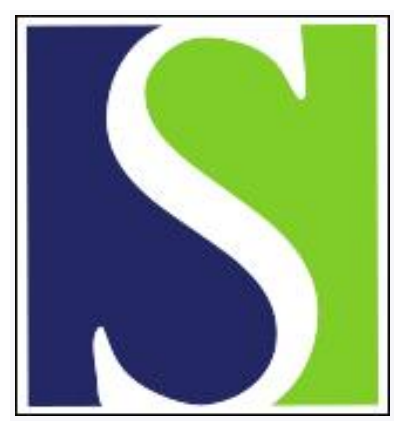

Scand J Work Environ Health 1982;8(1):70-73

https://doi.org/10.5271/sjweh.2494

Issue date: Mar 1982

Phenoxy acid herbicides cause peroxisome proliferation in Chinese hamsters.

by Vainio $\mathrm{H}$, Nickels J, Linnainmaa $\mathrm{K}$

Key terms: 2-4-dichlorophenoxyacetic acid; 2,4-D; 4-chloro-2-methylphenoxyacetic acid; China; clofibrate; experiment; hamster; herbicide; MCPA; peroxisome proliferation; phenoxy acid herbicide; toxicology

This article in PubMed: www.ncbi.nlm.nih.gov/pubmed/7134925

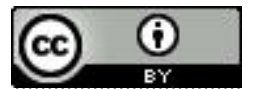




\title{
Phenoxy acid herbicides cause peroxisome proliferation in Chinese hamsters
}

\author{
by Harri Vainio, MD, Juha Nickels, MD, Kaija Linnainmaa, LSc ${ }^{1}$
}

\begin{abstract}
VAINIO H, NICKELS J, LINNAINMAA $\mathrm{K}$. Phenoxy acid herbicides cause peroxisome proliferation in Chinese hamsters. Scand $j$ work environ health 8 (1982) 70-73. An increase in either the size or amount of peroxisomes was obtained in the liver cells of Chinese hamsters after the animals were exposed to the phenoxy herbicides 2,4-dichlorophenoxyacetic acid (2,4-D) or 4-chloro-2-methylphenoxyacetic acid (MCPA). At the dose level studied, 2,4-D was found to be more potent than MCPA in increasing the number of peroxisomes. A phenoxy acid derivative, clofibrate, one of the peroxisome proliferators known to possess carcinogenic properties in rodents, appeared to be still more potent in inducing peroxisome proliferation than either of the herbicides studied. Further investigations are warranted to clarify the significance of peroxisome proliferation to the toxicity of phenoxy herbicides.
\end{abstract}

Key terms: 4-chloro-2-methylphenoxyacetic acid (MCPA), clofibrate, 2-4-dichlorophenoxyacetic acid $(2,4-\mathrm{D})$, experimental, toxicology.

Increased risk of soft tissue sarcomas has been reported among workers exposed to phenoxy acid herbicides $(3,4,5,7)$. The mutagenic activity of phenoxy herbicides has been, however, low or nonexisting in the studies performed (11). Recently, Reddy \& Azarnoff (10) suggested a novel class of chemical carcinogens not possessing mutagenic activity in bacterial mutagenesis assays but acting via the excessive production of hydrogen peroxide $\left(\mathrm{H}_{2} \mathrm{O} 2\right)$ and causing proliferation of peroxisomes. All the hypolipidemic peroxisome proliferators, including the widely used drug clofibrate, have also produced liver tumors in rats $(6,10)$. Furthermore, an overall excess of deaths from a variety of cancers, mainly gastrointestinal, has been reported for men receiving clofibrate therapy (6). Since clofibrate is closely related to phenoxy acids chemically, it was of interest to determine whether the commonly used phenoxy herbicides 2,4-dichlorophenoxyacetic acid (2,4-D) and 4-chloro-2-

1 Department of Industrial Hygiene and Toxicology, Institute of Occupational Health, Helsinki, Finland.

Reprint requests to: $\mathrm{Dr} \mathrm{H}$ Vainio, Institute of Occupational Health, Haartmaninkatu 1, SF00290 Helsinki 29, Finland. methylphenoxyacetic acid (MCPA) could also act as hepatic peroxisome proliferators.

\section{Materials and methods}

The test animals used in the study were 12 - to 20-week-old Chinese hamsters weighing $34-40 \mathrm{~g}$. They were bred in our laboratory from an outbred colony which originates from the Shell Research Centre (Sittingbourne, Kent, UK).

The phenoxy acid compounds considered were 2,4-D and MCPA, kindly provided by the manufacturer, Kemira Oy (Finland). Both treatment solutions consisted of commercial herbicide products wearing the trade names "Vesakontuho tasku" (solution containing 2,4-D) and "Vesakontuho MCPA" (solution containing MCPA). The amounts of 2,4-D and MCPA in the herbicide solutions are $550 \mathrm{~g} / \mathrm{kg}$ and 500 $\mathrm{g} / \mathrm{kg}$, respectively, and both chemicals contain only one effective compound.

A single dose of $100 \mathrm{mg} / \mathrm{kg}$ of the phenoxy acid compound dissolved in physiological saline was given daily for $9 \mathrm{~d}$ by gavage to three animals in each exposure group (the dose volumes ranged from 0.11 to $0.14 \mathrm{ml}$, depending on the 
weight of the animal). The three control animals were treated similarly with saline only. The animals were killed on the 10 th day of the experiment, $24 \mathrm{~h}$ after the last dose.

In the positive control experiment, the same single dose of $100 \mathrm{mg} / \mathrm{kg}$ of clofibrate (Klofiran ${ }^{\circledR}$, Remeda, Finland) dissolved in olive oil was injected subcutaneously into three animals daily for $7 \mathrm{~d}$ (the dose volumes ranged from 0.27 to $0.35 \mathrm{ml}$ ). The corresponding control animals were injected with olive oil only. The animals were killed on the eighth day of the experiment, $24 \mathrm{~h}$ after the last dose.

Two biopsies from each animal (three controls and three animals from each exposed group) were taken from the medial lobe immediately after the killing and fixed by immersion in $2 \%$ phosphatebuffered ( $\mathrm{pH}$ 7.4) glutaraldehyde for $2.5 \mathrm{~h}$.

Minced liver samples were washed for $0.5 \mathrm{~h}$ in phosphate buffer ( $\mathrm{pH}$ 7.4). The specimens were then incubated for $90 \mathrm{~min}$ at $38^{\circ} \mathrm{C}$ in a catalase localization medium [alkaline diaminobenzidine medium (8)] and washed in phosphate buffer $(\mathrm{pH} 7.4)$ overnight. The specimens were postfixed in $1 \%$ phosphate-buffered $(\mathrm{pH} 7.4)$ osmium tetroxide, dehydrated, and embedded in Epon. Ultrathin sections were stained with lead citrate and examined with a JEM-100 CX electron microscope.

The areas of peroxisomes were determined from 12 animals ( 3 per group) in electron micrographs $(6,600 \times)$ projected on a drawing board (final enlargement $100,000 \times)$. The outlines of the peroxisomes were drawn and used for later morphometric evaluation. The areas of 330 peroxisomes (between 80 and 90 in each group) were analyzed. For the calculation of the frequency of peroxisomes per unit area of cytoplasm, the peroxisomes of 40 hepatocytes, taken by random sampling, were counted (10 per group, total number of peroxisomes 5,754 ) in electron micrographs with an enlargement of $3,000 \times$.

The areas of peroxisomes and hepatocytes were examined with the aid of a semiautomatic measuring device (Hipad digitizer and $\mathrm{ABC}-80$ data processing unit). The statistical difference from the control group was calculated with Cochran's approximate t-test (2).

\section{Results}

The mean size of the peroxisomes of the control rats was $1.38 \mu \mathrm{m}^{2}$ (table 1). The 2,4-D treatment increased the mean area slightly but not significantly to $1.46 \mu \mathrm{m}^{2}$. A significant increase in size was seen after MCPA and clofibrate treatment, to 2.02 and $2.37 \mu \mathrm{m}^{2}$, respectively.

The mean frequency of peroxisomes per $100 \mu \mathrm{m}^{2}$ of cytoplasm was 17.7 in the controls (table 2). MCPA treatment increased the frequency slightly but not

Table 1. Effect of 4-chloro-2-methylphenoxyacetic acid (MCPA), 2,4-dichlorophenoxyacetic acid (2,4-D), and clofibrate on the mean size of peroxisomes.

\begin{tabular}{llllll}
\hline \multirow{2}{*}{ Exposure a } & \multicolumn{2}{l}{ Peroxisome size $\left(\mu \mathrm{m}^{2}\right)$} & & \\
\cline { 2 - 3 } & Mean & SD & & $t^{b}$ \\
\hline Control & 1.38 & 0.48 & 80 & \\
MCPA & 2.02 & $0.84^{*}$ & 80 & 5.92 \\
2,4-D & 1.46 & $0.50 \mathrm{NS}$ & 80 & 1.03 \\
Clofibrate & 2.37 & $1.17^{*}$ & 90 & 9.57 \\
\hline
\end{tabular}

a There were three animals in each group.

b The statistical significance of the difference from the controls was determined by Cochran's approximate t-test (2).

$* \mathrm{p}<0.001$, NS $=$ not significant.

Table 2. The effect of 4-chloro-2-methylphenoxyacetic acid (MCPA), 2,4-dichlorophenoxyacetic acid $(2,4-D)$, and clofibrate on the peroxisome density per $100 \mu \mathrm{m}^{2}$ of hepatocytic cytoplasm.

\begin{tabular}{lccc}
\hline \multirow{2}{*}{ Exposure } & \multicolumn{2}{c}{$\begin{array}{c}\text { Number of } \\
\end{array}$} & \multicolumn{2}{c}{ peroxisomes $/ 100 \mu \mathrm{m}^{2} \mathrm{a}$} & $\mathrm{t} \mathrm{t}$ \\
\cline { 2 - 3 } & Mean & $\mathrm{SD}$ & \\
\hline & & & \\
Control & 17.7 & 3.7 & \\
MCPA & 18.5 & $2.8 \mathrm{NS}$ & 0.54 \\
2,4-D & 27.3 & $4.9^{*}$ & 4.94 \\
Clofibrate & 37.0 & $6.7^{*}$ & 7.97 \\
\hline
\end{tabular}

a In each group of three animals, the number of peroxisomes in 10 cells was counted, and the results are given as the mean and standard deviation of the peroxisomes per $100 \mu \mathrm{m}^{2}$ unit area. The total number of counted peroxisomes per group varied from 760 to 2,555 .

b The statistical significance of the difference from the controls was determined by Cochran's approximate t-test (2).

* $p<0.001, \mathrm{NS}=$ not significant. 

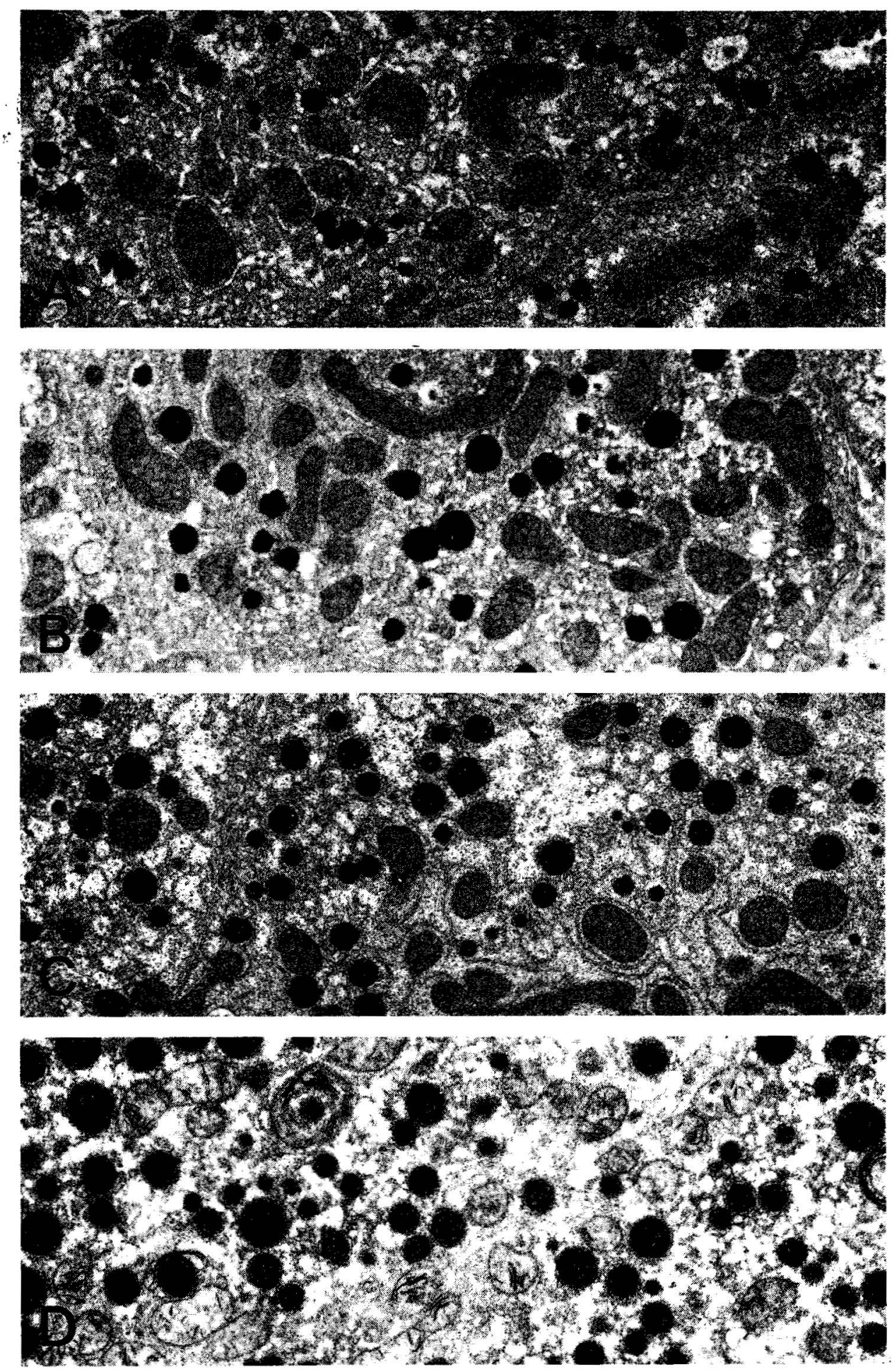

Fig 1. Chinese hamster hepatocytes, alkaline diaminobenzidine incubation $(7,800 \times)$. (A. control: normal amount of dark staining peroxisomes; B. after 4-chloro-2-methylphenoxyacetic acid (MCPA) treatment: peroxisomes enlarged and slightly increased in number; C. 2,4-dichlorophenoxyacetic acid (2,4-D) treatment: enlargement and proliferation of peroxisomes; D. clofibrate-treated hepatocyte: clearly proliferated and enlarged peroxisomes) 
significantly to 18.5. Clofibrate and 2,4-D had a significant effect on the number of peroxisomes, increasing it to 37.0 and 27.3 per $100 \mu \mathrm{m}^{2}$, respectively. The size increase and proliferation of peroxisomes are also illustrated in fig 1.

A slight increase in the smooth, and decrease in the rough, endoplasmic reticulum was seen after clofibrate treatment, the reticulum being normal in the other groups. Mitochondria were normal in all cases.

\section{Discussion}

Little is known about the possible mechanism by which exposure to phenoxy acid herbicides may be associated with increased risk of soft-tissue sarcoma and malignant lymphoma, as suggested on the basis of epidemiologic studies done in Sweden $(3,4,5)$. Although in many cases mutagenic and carcinogenic effects are experimentally correlated (1), the phenoxy acid herbicides do not appear to have direct interaction with DNA (deoxyribonucleic acid). Phenoxy acids are not known to bind to DNA, neither have they possessed mutagenic activity in the Salmonella/microsome assay (11).

The present data show that the phenoxy herbicides 2,4-D and MCPA are able to increase either the size or amount of peroxisomes in the liver cells of Chinese hamsters. Thus the possibility exists that phenoxy acid herbicides could act indirectly by a mechanism similar to the one suggested recently for tumor initiation by known peroxisome proliferators. This novel class of chemical carcinogens includes, eg, clofibrate, a phenoxy acid derivative, and other related hypolipidemic drugs, as well as phthalate ester di(2ethylhexyl)phthalate $(8,10)$. Their mechanism of action has been suggested to occur via excessive production and/or breakdown of $\mathrm{H}_{2} \mathrm{O}_{2}$. Thus the initiation of neoplastic transformation would be the result of continued production of DNA-damaging oxygen radicals as a result of the persistent proliferation of peroxisomes.

In summary, the data obtained suggest that the phenoxy herbicides 2,4-D and MCPA act as peroxisome proliferators. Taking the existing evidence into account, further studies should be carried out to clarify the potential significance of this peroxisome proliferation in the toxicity of phenoxy herbicides.

\section{Acknowledgments}

We thank Ms T Stjernvall for her skillful technical assistance.

The study was supported by the Academy of Finland.

\section{References}

1. Ames B. Identifying environmental chemicals causing mutations and cancer. Science 204 (1979) 587-593.

2. Cochran WG. Approximate significance levels of the Behrens-Fisher test. Biometrics 20 (1964) 191-195.

3. Eriksson M, Hardell L, Berg NO, Möller $T$, Axelson $O$. Soft-tissue sarcomas and exposure to chemical substances: A casereferent study. Br $\mathrm{j}$ ind med (in press).

4. Hardell L. Epidemiological studies on softtissue sarcoma and malignant lymphoma and their relation to phenoxy acid or chlorophenol exposure. University of Umeå, Umeå 1981, pp 1-139. (University medical dissertations, new series no 65).

5. Hardell L, Sandström A. Case-control study: Soft-tissue sarcomas and exposure to phenoxyacetic acids or chlorophenols. $\mathrm{Br} \mathrm{j}$ cancer 39 (1979) $711-717$.

6. International Agency for Research on Cancer. IARC monographs on the evaluation of the carcinogenic risk of chemicals to humans: Some pharmaceutical drugs. Lyon 1980, pp 39-58. (No 24).

7. Moses M, Selikoff IJ. Soft-tissue sarcomas, phenoxy herbicides, and chlorinated phenols. Lancet 1 (1981) 8234.

8. National Institutes of Health. Bioassay of di(2-ethylhexyl)-phthalate for possible carcinogenicity. (NIH publication no 81-1773).

9. Novikoff AB, Novikoff PM, Davis C, Quintana N. Studies on microperoxisomes: II A cytochemical method for light and electron microscopy. J histochem cytochem 20 (1972) 1006-1023.

10. Reddy JK, Azarnoff DL. Hypolipidaemic hepatic peroxisome proliferators form a novel class of chemical carcinogens. Nature 283 (1980) 397-398.

11. Seiler J. The genetic toxicology of phenoxy acids other than 2,4,5-T. Mutat res 55 (1978) $197-226$. 